\title{
Treatment of Water Effluents Using Silver Nanoparticles
}

\begin{abstract}
The water from industries with potential hazardous organic matters when discharged into the water bodies cause undesirable effects to the environment, aquatic life and human health. So it is necessary to treat waste water prior to their disposal. Degradation of organic pollutants is a major concern in the present scenario due to its stability, fastness to sunlight, resistance to degrading agents or microbial attack. It is mainly achieved by silver metal nanoparticles synthesised by green route. Degradation of dyes using metal nanoparticles is an environmental benign method. Silver metal nanoparticles show high catalytic potential due to its unique property of smaller structure and large surface to volume ratio. This review provides a detailed report of the degradation of various organic pollutants by phyto synthesised silver metal nanoparticles.
\end{abstract}

Volume 2 Issue 5 - 2018

\author{
Mamatha Susan Punnoose, Beena Mathew \\ Mahatma Gandhi University, India
}

Correspondence: Beena Mathew, School of Chemical Sciences, Mahatma Gandhi University, Kottayam-686560, Kerala, India, Email beenamathiw@mgu.ac.in

Received: April 30, 2018 | Published: October 12, 2018

\section{Introduction}

Water pollution is an environmental issue which is gaining global attention in the recent years. The major source of water pollution are the effluents from textile dyeing and finishing industries. Because of drastic changes in customer's demands, the textile industry is a challenge to use high quantity of dyes and auxiliaries that are necessary for modern textile processing. The used water contains various constituents such as dyes and chemicals which are directly released into the sources of water which gets contaminated and thus resulting in water pollution. The discharge of untreated waste into the water bodies has raised much concern because of potential health hazards associated with the entry of toxic components into the food chains of humans and animals. In our day to day demand for potable water is increasing, which is placing an increasing burden on nature's availability of water resource, has forced for new and efficient methods for water treatment.

\section{Sources and effect of dye pollutants}

Synthetic dyes and organic colorants used in paint, plastic, paper, printing, textiles, drug, leather and food related industries are the major organic pollutants in water. ${ }^{1-3}$ Nitrophenols and their derivatives are produced from agricultural and industrial sources including those manufacturing dyes, explosives, pesticides and other products. ${ }^{4,5}$ Dyes are the chemical substances used to impart colour to fabrics, foods and other objects for their beautification and distinction. They are capable of getting fixed to the fabrics permanently and are resistant to the action of water, sunlight, soap, acid and alkalies. The colour of a dye is mainly due to the presence of chromophores and auxochromes. Depending upon the characteristic structural units constituting the dyes, these are classified as azo, phthalein, triphenyl methane, indigoid, anthraquinone and nitro dyes. The dyes are also classified on the basis of their characteristics like fastness to light, resistance to acids and alkalies and the kind of fibre they can dye as acidic, basic, direct, disperse, vat, insoluble azo and mordant dyes. More than $7 \times 10^{5}$ tons of approximately 1,00,000 types of dyes are produced annually. ${ }^{6}$ The toxic and carcinogenic effect of dyes causes eutrophication, reduces reoxygenation, and makes severe damage to the aquatic organisms by hindering the infiltration of sunlight and interfering the growth of aquatic species. ${ }^{7,8}$ Dyes are not readily biodegradable as they are resistant to microbial attack, aerobic digestion and are stable to heat, light and oxidising agents. The highly persisting nature of organic contaminants even at their very low concentrations make the water more detrimental for use. Therefore, it is essential to remove or minimize dyes to permissible concentration prior to discharge.

\section{Different methods for removal of dye effluents in water bodies}

\section{a) Physical}

Adsorption is the most efficient method for the removal of dyes, odors, organic, and inorganic pollutants from industrial effluents and is found to be superior to other techniques in terms of initial cost, flexibility and simplicity of design, ease of operation and insensitivity to toxic pollutants. ${ }^{9}$ Adsorption does not require an additional pretreatment step before its application and process does not result in the formation of any harmful substance. In ion exchange treatment of dye-containing effluents, wastewater is passed over the ion exchange resin until the available exchange sites are saturated. ${ }^{10}$ Both cation and anion dyes can be removed from dye-containing effluent using this approach. ${ }^{11}$ Advantages of this method include no loss of adsorbent on regeneration, reclamation of solvent after use and the removal of soluble dyes. Membrane separation including ultrafiltration, nanofiltration and reverse osmosis have been increasingly used recently for the treatment of effluents due to its ease of operation. ${ }^{11}$ Electrotreatments such as electrodialysis has also contributed to environmental protection. ${ }^{12}$

\section{b) Chemical}

Chemical methods include coagulation or flocculation combined with flotation and filtration, precipitation-flocculation with $\mathrm{Fe}(\mathrm{II}) /$ $\mathrm{Ca}(\mathrm{OH})_{2}$, electroflotation, electrokinetic coagulation, conventional oxidation methods by oxidizing agents (ozone), irradiation or electrochemical processes. ${ }^{13-16}$ These chemical techniques are often expensive, and although the dyes are removed, accumulation of concentrated sludge creates a disposal problem. ${ }^{17}$ Although these methods are efficient for the treatment of water contaminated with pollutants, they are very costly and commercially unattractive. 


\section{c) Biological}

Biological methods for degradation of dyes found to be more economical than physical and chemical methods. Biodegradation methods such as fungal decolourization, microbial degradation, adsorption by microbial biomass and bioremediation systems are commonly applied to the treatment of industrial effluents because many microorganisms such as bacteria, yeasts, algae and fungi are able to accumulate and degrade different pollutants. ${ }^{18,19}$ However, their application is often restricted because of technical constraints such as requirement of large land area, less flexibility in design and operation..$^{20}$ Although many organic molecules are degraded, many others are recalcitrant due to the complexity of their structure and also due to their synthetic organic origin..$^{21}$ In particular, due to the xenobiotic nature, azo dyes are not totally degraded.

\section{d) Photocatalytic degradation}

Sunlight is an abundantly available natural source of energy which can be conveniently exploited for the photodegradation of pollutants and can make the process economically more viable. ${ }^{22,23}$ Dyes can be degraded in the presence of photocatalyst such as metal nanoparticles upon irradiation with visible light because of their absorption in the visible region and is advantageous due to its quick oxidation, without the formation of polycyclic products and oxidation of pollutants. UV irradiation acts as another source for organic dye degradation by photocatalysts including $\mathrm{TiO}_{2}{ }^{24}$ and $\mathrm{ZnO}^{25} \mathrm{TiO}_{2}$ is of particular interest due to its low cost and high stability. But they show a relatively large energy band-gap and only absorbs UV region, while the UV light only contribute to less than $10 \%$ of total solar radiations; the visible light, on the other hand, contribute to $50 \%$ of the solar radiations. It is a crucial drawback for the $\mathrm{TiO}_{2}$ based photo catalysts. ${ }^{26} \mathrm{ZnO}$ is unstable due to incongruous dissolution to yield $\mathrm{Zn}(\mathrm{OH})_{2}$ on the $\mathrm{ZnO}$ particle surfaces and thus leading to catalyst inactivation. ${ }^{27} \mathrm{Photocatalysts} \mathrm{like}$ $\mathrm{SnO}_{2}, \mathrm{ZrO}_{2}, \mathrm{CdS}, \mathrm{MoO}_{3}, \mathrm{WO}_{3}, \mathrm{RuO}_{2}, \mathrm{Co}_{3} \mathrm{O}_{4}, \mathrm{Cu}_{2} \mathrm{O}, \mathrm{SiO}_{2}, \alpha-\mathrm{Fe}_{2} \mathrm{O}_{3}$, $\mathrm{Mn}_{2} \mathrm{O}_{3}$ and $\mathrm{Fe}_{3} \mathrm{O}_{4}$ have shown negligible activity. ${ }^{28}$ The photocatalytic activity of these could be improved under UV and visible illumination by incorporation of metal nanoparticles of silver, gold or iron to broaden the absorption of solar radiations. ${ }^{29}$ The size, shape, large surface area to volume ratio and mass dependent reactivity has made metal nanoparticles as effective catalyst. ${ }^{30}$ Conventional chemical synthesis of these nanoparticles is not an eco-friendly method. Thus, a cost effective, clean, non-toxic and biogenic approach of synthesis of nanoparticles gain importance.

e) Catalytic degradation by metal nanoparticles with the aid of reducing agent

An alternative method for organic dye reduction utilises the electron donating capacity of transition metal nanoparticles such as silver, gold, iron, nickel, palladium and platinum in the presence of reducing agents like $\mathrm{LiAlH}_{4}, \mathrm{NaBH}_{4}$ or $\mathrm{H}_{2} \mathrm{O}_{2}$. Silver metal nanoparticles have high efficient catalytic activities because of their unique properties such as extreme small dimensions, large surface to bulk ratio, large dispersitivity and ability to transfer electrons between the donor and acceptor electon relay system..$^{30,31}$ Nowadays biogenic silver nanocatalysts are widely used for the effective removal of dye contaminants.

\section{Need for the green synthesis of silver nanoparticles}

Metal nano particles can be synthesised by using top-down (physical) and bottom-up (chemical and biological) methodologies.
Most popular physical and chemical nanoscale synthetic methods involve laser ablation, mechanical grinding, photochemical, solvothermal, co-precipitation, microemulsion, sol-gel, physiochemical reduction, electrochemical and sonochemical process. ${ }^{32,33}$ Majority of these methods involve the use of toxic chemicals and severe reaction conditions, which causes chemical toxicity and environmental pollution. ${ }^{34}$ This increases the focus on synthesis using biomediated green routes. Biosynthesis of metal nanoparticles are eco friendly which involves the use of plant extracts, enzymes, cell cultures or microorganisms such as bacteria, fungi, algae, yeast and virus. ${ }^{35,36}$ Among these, plant products is the most adopted method as phytochemicals are the natural resource for the synthesis of metal nanoparticles, much safer to handle, widely available and ability to act as both stabilization and reduction agent. ${ }^{37}$ Azadirachta indica leaves, Camellia sinensis, Capsicum annuum L., Cinnamomum camphora leaves, Datura metel, Emblica officinalis fruit, Ocimum sanctum leaves are few among them. ${ }^{38,39}$ Moreover, use of plant extracts also reduces the cost of microorganism isolation and culture media preparation. The following gives the account of degradation of organic pollutants by biogenically synthesised silver nanoparticles.

\section{Mechanisms of dye degradation}

\section{Catalytic degradation by silver nanoparticles using reducing agents}

The process of dye degradation by silver nanocatalyst through reducing agent like $\mathrm{NaBH}_{4}$ can be explained by electron transfer mechanism. During degradation, the catalysis process occurs on the surface region of metals, therefore the surface area availability will increase significantly and in turn improve the efficiency of the catalyst. ${ }^{40}$ The reductant molecules and dye molecules are probably adsorbed on the large surface of silver nanoparticles without affecting their activity. When the reducing agent $\mathrm{NaBH}_{4}$ is adsorbed on the nanoparticles, its reductive potential decreases, as $\mathrm{NaBH}_{4}$ is a strong nucleophile. On the other hand, when dye molecules get adsorbed on nanoparticles, their reduction potential increase, as the molecules are electrophilic in nature and hence, when both the species are adsorbed on nanoparticles they become more negative for $\mathrm{NaBH}_{4}$ molecules and more positive for dye molecule. The biogenic silver nanoparticles support the "electron shuttling" from the donor to the acceptor molecules and thus act as an effective substrate for the electron relay process ${ }^{41}$ During electron transfer reaction, the $\mathrm{BH}_{4}^{-}$ions are simultaneously adsorbed on the surface of metal nanoparticles and thus electron transfer occurs from $\mathrm{BH}_{4}^{-}$ions to dye through the nanoparticles, resulting in the destruction of the dye chromophore structure to form small species such as acetamide, $\mathrm{CO}_{2}, \mathrm{H}_{2} \mathrm{O}$, which are less hazardous than the organic pollutant. ${ }^{42}$

\section{Photocatalytic degradation by silver nanoparticles}

The photocatalytic mechanism can be related by two parts namely, photo and catalysis. The first portion related to photon absorption, charge carrier creation and dynamics. The second portion is related to surface radical formation and surface reactivity between $\mathrm{O}_{2}$, $\mathrm{H}_{2} \mathrm{O}$ and organic molecules. ${ }^{43}$ Upon photon absorption by silver nanoparticles, an electron gain energy and get excited from valence band $(\mathrm{VB})$ to conduction band $(\mathrm{CB})$, leaving a positively charged hole in the valence band $\left(\mathrm{h}_{\mathrm{VB}}^{+}\right)$. The valence band holes react with the chemisorbed $\mathrm{H}_{2} \mathrm{O}$ molecules to form reactive species such as $\mathrm{OH}^{*}$ radicals. An electron in the conduction band $\left(\mathrm{e}_{\mathrm{CB}}^{-}\right)$of the nanoparticles reacts with dissolved oxygen molecules in the reacting medium and 
converted into oxygen anion radicals. ${ }^{44} \mathrm{HO}_{2} \cdot$ radicals were generated on protonation of superoxide radical anions $\mathrm{O}_{2} \cdot{ }^{-}$. The molecular oxygen, adsorbed on the surface of the photocatalysts prevents the hole-electron pair recombination process ${ }^{45}$ Recombination of holeelectron pair decreases the rate of photocatalytic degradation. The hydroxyl radicals $\left(\mathrm{OH}{ }^{\circ}\right)$ and super oxide radical anions $\left(\mathrm{O}_{2}^{--}\right)$are powerful oxidizing agents capable of attacking dye molecules and degrade them into small molecules such as $\mathrm{CO}_{2}, \mathrm{H}_{2} \mathrm{O}$, and $\mathrm{NH}_{3}$, which are not particularly toxic.

The degradation mechanism is as follows

1. Absorption of photons by silver nanoparticles

$$
\text { Ag nanoparticles }+h g \rightarrow h_{V B}^{+}+e_{C B}^{-}
$$

2. Production of $\mathrm{OH}$ radicals

$$
\begin{aligned}
& \mathrm{OH}^{-}+h_{V B}^{+} \rightarrow \mathrm{OH}^{\cdot} \\
& \mathrm{H}_{2} \mathrm{O}+h_{V B}^{+} \rightarrow \mathrm{OH}^{\cdot}+H^{+}
\end{aligned}
$$

3. Oxidation of the organic pollutant via successive attack by the $\mathrm{OH} \bullet$ radicals

$$
\text { dye }+\mathrm{OH} \bullet \rightarrow \text { dye }(\text { intermediates })+\mathrm{H}_{2} \mathrm{O}
$$

dye $+h_{V B}^{+} \rightarrow$ dye $e^{+\cdot} \rightarrow$ Degradation products $\mathrm{NH}_{4}^{+}, \mathrm{SO}_{4}{ }^{2-}, \mathrm{CO}_{2}$

4. Oxygen reduction

$$
\mathrm{O}_{2}+e^{-}{ }_{C B} \rightarrow \mathrm{O}_{2} \cdot
$$

\section{Degradation of methylene blue}

Methylene blue degradation at $664 \mathrm{~nm}$ corresponding to $n-\pi *$ transition is studied using UV-vis. spectrophotometer, in the presence and absence of different biogenic silver nanocatalysts. The colour change from blue to colourless leuco methylene blue infer the complete degradation of dye. Silver nanoparticles acts as a electron mediator between donor $\left(\mathrm{NaBH}_{4}\right)$ and electron acceptor (Methylene blue dye). Silver nano catalyst is believed to have redox potential in between the values of acceptor and donor. ${ }^{46}$ In the catalytic degradation by Convolvulus arvensis mediated silver nano, reaction was completed within 20 minutes and rate of the reaction is $0.108 \mathrm{~min}^{-1} .^{47}$ The high catalyic efficiency of silver nanoparticles is due to the large number of active sites provided by high surface area of the very small nanoparticles ${ }^{47}$ The catalytic action of silver nanoparticle is attributed to the 'electron relay effect'. Reduction of dye by $\mathrm{NaBH}_{4}$ without nano catalyst is not effective and required months for the degradation. The reduction of dye by sodium borohydride in the presence of Soymida febrifuga silver nanocatalyst was completed in less than 20 minutes. ${ }^{48}$ In the absence of Aglaia elaeagnoide ${ }^{49}$ mediated catalyst, reduction of dye was not effective as the original colour persisted for more than 20 minutes. In the presence of catalyst, degradation completed within 5 seconds. Addition of nano catalyst lowers the bond dissociation energy and causes efficient electron transfer between borohydride ions to the dye acceptor. ${ }^{50}$ The decolurisation of dye by Dillenia indica $^{51}$, Polygonum hydropiper ${ }^{52}$, Cucurma longa ${ }^{53}$ mediated silver nanocatalyst was completed within 30,15 and 60 minutes respectively. As the concentration of the Biophytum sensitivum synthesised AgNP increased between 0.020 to $0.050 \mathrm{mg} / \mathrm{ml}$, keeping the concentration of dyes and $\mathrm{NaBH}_{4}$ a constant, the rate of dye degradation increased and were 0.9066 and $1.3080 \mathrm{~min}^{-1}$ respectively. As concentration of $\mathrm{NaBH}_{4}$ is much higher than that of dyes, its concentration remains practically constant and the degradation reaction is considered to follow pseudo first order kinetics. ${ }^{54}$ The degradation by Punica granatum nanocatalyst with $\mathrm{NaBH}_{4}$ followed first order kinetics and rate of degradation is $0.1904 \mathrm{~min}^{-1} .{ }^{5}$ The degradation constant for the efficient reduction catalysed by Zanthoxylum armatum derived silver nanoparticle is $1.44 \times 10^{-3} \mathrm{~min}^{-1} .^{56}$

\section{Degradation of azo dyes}

Methyl orange, methyl red and congo red are the commonly used azo dyes in textile industries and are also used as indicators in various industries. These are highly toxic and are harmful to plants and human beings. So its effective degradation is a need. The aqueous solution of methyl orange is orange red in colour. The UV-vis. spectrum of aqueous solution of the methyl orange and methyl red showed strong absorptions at $465 \mathrm{~nm}$ and $490 \mathrm{~nm}$ respectively. Congo red in water medium shows surface plasmon resonance bands at $498 \mathrm{~nm}$ and 338 $\mathrm{nm}$ corresponding to $\pi \rightarrow \pi *$ and $n \rightarrow \pi *$ electron transitions associated with azo group. An increase in the rate of methyl orange degradation by Punica granatum nanocatalyst with the help of $\mathrm{NaBH}_{4}$ was observed because of the excellent catalytic activity of nanoregime particles due to their relative high surface to volume ratios. The degradation followed first order kinetics and rate of degradation is $0.5477 \mathrm{~min}^{-1}{ }^{15}$ In the absence of nanocatalyst prepared from Tangerine peel extract, degradation by $\mathrm{H}_{2} \mathrm{O}_{2}$ or $\mathrm{NaBH}_{4}$ was found to be negligible slow rate and in its presence the rate became appreciably high. ${ }^{57} \mathrm{As}$ Biophytum sensitivum mediated silver catalyst concentration was varied between 0.02 to $0.040 \mathrm{mg} / \mathrm{ml}$ the degradation rate was found to be 0.1953 and $0.2758 \mathrm{~min}^{-1}$ respectively. The degradation followed pseudo first order kinetics. ${ }^{54}$ Catalytic degradation by the reductant $\mathrm{NaBH}_{4}$ alone results no change in the characteristic absorption peak at $465 \mathrm{~nm}$ even upto 6 hours. Addition of green synthesised silver nanoparticles using Mussaenda erythrophylla into the solution containing dye and $\mathrm{NaBH}_{4}$ caused a rapid dip in the absorbance peak at $465 \mathrm{~nm} .{ }^{58}$ Faster degradation is attributed to the large surface area, "electron shuttling" of electrons between donor and acceptor and assistance in diminishing the activation barrier provided by the silver nanoparticles. Surface plasmon resonance band showed a blue shift in absoption peak from 465 to $440 \mathrm{~nm}$ during the dye degradation due to the surface alterations arising due to electron relay process. ${ }^{58}$ In presence of tannic acid ${ }^{59}$ stabilised catalyst, $82 \%$ degradation was completed within 2 minutes. While in uncatalysed reaction, no such significant degradation was observed even after 150 minutes. The catalysed reaction found to be faster due to electron relay of silver catalyst from $\mathrm{BH}_{4}^{-}$ions to the methyl orange dye. ${ }^{55}$ Cucurma longa mediated silver nano showed complete degradation within 3 minutes. ${ }^{53}$ The rate constant for the degradation of methyl orange and methyl red by Zanthoxylum armatum mediated catalyst were $1.86 \times 10^{-3} \mathrm{~min}^{-1}$ and $1.03 \times 10^{-3} \mathrm{~min}^{-1}$ respectively. ${ }^{56}$ The degradation of methyl orange and congo red did not even started by the reducing agent $\mathrm{NaBH}_{4}$ without nano catalyst. Only after the addition of silver nanoparticles, catalytic reductive degradation of the dyes commenced and completed within $30 \mathrm{~min}$ for both dyes. Absorbance peak of the dyes degraded in a fast manner as the reaction time increased. Dye degradation followed Langmuir Hinshelwood model and pseudo first order kinetics with rate constants 0.0795 and $0.1178 \mathrm{~min}^{-1}$ respectively for congo red and methyl orange. Silver nano catalyst was the electron transfer mediator, and provided more catalytic sites due to high surface to volume ratio, lowered activation energy and fast discoloration of dyes. ${ }^{60}$ Hyphaene thebaic $^{61}$ and Aglaia elaeagnoidea ${ }^{49}$ mediated silver nanocatalysts in the presence of $\mathrm{NaBH}_{4}$ degraded almost $80 \%$ and $99 \%$ of Congo red. Amaranthus gangeticus ${ }^{62}$ mediated silver nano catalyst showed high efficiency in catalytic degradation of Congo red by strong ethanolic borohydride reductant. Degradation in the absence of nanocatalyst is 
very slow due to the inefficient transfer of electron from the reductant to the dye which was usually done by the catalyst. ${ }^{62}$ Within 24 hours of incubation, Phaseolus vulgaris and Brassica oleracea capitata mediated AgNP at varying concentrations showed almost and 50$60 \%$ degradations of Congo red. Due to the presence of azo bond and structural complexity of Mordant black 17, the degradation was not much effective by silver nanocatalyst at both the concentrations..$^{63,64}$

\section{Degradation of nitro compounds}

Plant based metal nanoparticles are effective for the degradation of nitro compounds (Table 1). Characteristic absorption peaks of onitro anilines are at $283 \mathrm{~nm}$ and $412 \mathrm{~nm}$. In the presence of sodium borohydride, degradation was very slow. Upon the addition of Indigofera tinctoria mediated nanocatalyst in presence of the reducing agent, o-nitro aniline was reduced to 1, 2 benzenediamine. Intensity of the characteristic peak of p-nitroaniline at $380 \mathrm{~nm}$ decreased and a new peak was formed at $240 \mathrm{~nm}$ which indicates the complete conversion of $\mathrm{p}$-nitroaniline to phenelenediamine. Both reductions follow puseudo first order kinetics with high correlation coefficients. Rate constants for the respective reactions are $0.0975 \mathrm{~min}^{-1}$ and 0.1823 $\min ^{-1}{ }^{65}$ The nano catalyst took part in the electron relay between the electron donor (borohydride ions) and organic electron acceptor moieties. ${ }^{46}$ Elephantopus scaber mediated silver nanoparticles showed effective reduction of 4-nitrophenol, o-nitro aniline, p-nitro aniline by sodium borohydride. All reductions followed pesuedo first order kinetics and rate constants for the respective reduction reactions are $0.2794,0.0751,0.2788 \mathrm{~min}^{-1}{ }^{66}$ The aqueous solution of 4-nitro phenol is pale yellow in colour and its UV-vis. Absorption spectrum showed peaks at $317 \mathrm{~nm}$ and $227 \mathrm{~nm}$ respectively due to $\mathrm{n} \rightarrow \pi^{*}$ and $\pi \rightarrow \pi^{*}$ transitions. Majority of organic pollutants like nitrophenol and their respective derivatives are chiefly formed during the production of pesticides, insecticides, herbicides and synthetic dyes in their industries. ${ }^{67}$ In the presence of $\mathrm{NaBH}_{4}$ as reducing agent, the colour of 4-nitro phenol solution instantly changed to greenish yellow and the absorption maximum at $317 \mathrm{~nm}$ was red shifted to $400 \mathrm{~nm}$ due to the formation of 4-nitrophenolate ions in the alkaline condition caused by the addition of $\mathrm{NaBH}_{4}{ }^{68}$ Hydrogenation of 4 nitro phenol to 4-amino phenol was carried out by alkaline tapioca starch $^{69}$ and Lawsonia inermis ${ }^{70}$ capped silver nano using $\mathrm{NaBH}_{4}$. In the presence of catalyst, peak at $400 \mathrm{~nm}$ vanished along with the decolouration of bright yellow colour of 4-nitro phenolate ions and a new peak at $298 \mathrm{~nm}$ emerged due to the formation of 4-amino phenol. ${ }^{71}$ Though the reduction of 4-nitro phenol to 4-amino phenol by aqueous $\mathrm{NaBH}_{4}$ is thermodynamically favorable, the presence of the kinetic barrier due to large potential difference between donor and acceptor molecules decreased the feasibility of this reaction..$^{72}$ The metal nanoparticles catalyzed this reaction by facilitating electron relay from the donor $\mathrm{BH}_{4}^{-}$to acceptor 4-nitophenol to overcome the kinetic barrier and results in the appearance of a new adsorption peak at $298 \mathrm{~nm}$ corresponding to the formation of $4-$ aminophenol. ${ }^{49}$ Both $\mathrm{BH}_{4}^{-}$and 4-nitro phenolate ions are adsorped on the catalytic surface. Reduction was achieved by the lowering of activation energy and thus nanoparticles acted as efficient catalysts. ${ }^{70}$ Chenopodium aristatum $L$. capped silver nanoparticles was effective catalyst for the reduction of 4-nitro phenol. Plot of $\ln \left(\mathrm{C}_{\mathrm{t}} / \mathrm{C}_{\mathrm{o}}\right)$ with time for degradation in presence of silver nano catalyst gave a linear relation and followed Langmuir and Hinshelwood model kinetics. ${ }^{73}$ Since the amount of $\mathrm{NaBH}_{4}$ used in reduction greatly exceeds that of 4-nitrophenol, the concentration of $\mathrm{NaBH}_{4}$ stayed practically constant throughout the course of the reaction. ${ }^{71}$ The degradation followed pseudo-first order kinetics with respect to 4-nitrophenol concentration. The Hyphaene thebaica ${ }^{61}$ Dillenia indica, ${ }^{51}$ Actinidia deliciosa 72 mediated silver nanoparticles could facilitate electron transfer from $\mathrm{BH}_{4}^{-}$ion to the 4-nitrophenol, lead to 4-aminophenol formation. Fast electron transfer occured in presence of catalyst, which gave rise to fast reaction process. ${ }^{51}$

Table I Catalytic degradation by biosynthesised silver nanoparticles using $\mathrm{NaBH}_{4}$ as reducing agent

\begin{tabular}{|c|c|c|c|c|}
\hline Plant species & Plant part & Organic effluent & Remarks & Ref. \\
\hline Anacardium occidentale & Testa & Congo red, Methyl orange & Followed Langmuir- Hinshel wood model kinetics. & 60 \\
\hline Aglaia elaeagnoidea & Flower & $\begin{array}{l}\text { Methylene blue, Congo } \\
\text { red,4-Nitro phenol }\end{array}$ & Followed pseudo first order kinetics. & 49 \\
\hline \multirow[t]{2}{*}{ Biophytum sensitivum } & Leaf & Methylene blue, & Followed pseudo first order kinetics & 54 \\
\hline & & Methyl orange & & \\
\hline Soymida febrifuga & Leaf & Methylene blue & Degradation completed within 20 minutes & 48 \\
\hline Tangerine & Peel & Methyl orange & Degradation was fast in presence of nanocatalyst & 57 \\
\hline \multirow[t]{2}{*}{ Zanthoxylum armatum } & Leaf & $\begin{array}{l}\text { Safranine } O \text {, Methyl red, } \\
\text { Methyl orange, }\end{array}$ & $\begin{array}{l}\text { Degradation constants are } 1.02 \times 10-3,1.03 \times 10-3 \text {, } \\
1.86 \times 10-3,1.44 \times 10-3 \text { min- I respectively }\end{array}$ & 56 \\
\hline & & Methylene blue & & \\
\hline Mussaenda erythrophylla & Leaf & Methyl orange & $\begin{array}{l}\text { Degradation was mainly due to nanoparticle mediated } \\
\text { transfer of electrons }\end{array}$ & 58 \\
\hline Tannic acid & $\begin{array}{l}\text { Analytical } \\
\text { grad }\end{array}$ & Methyl orange & $82 \%$ degradation complete within 2 minutes & 59 \\
\hline Cucurma longa & Tubes & $\begin{array}{l}\text { Methyl orange, Methylene } \\
\text { blue }\end{array}$ & Degradation completed within few minutes & 53 \\
\hline Convolvulus arvensis & Leaf & Methylene blue & Rate constant is $0.108 \mathrm{~min}-1$ & 47 \\
\hline Aglaia elaeagnoidea & Flower & Congo red & Shown $99 \%$ degradation & 49 \\
\hline Gmelina arborea & Fruit & Methylene blue & Complete reduction occur within minutes & 50 \\
\hline
\end{tabular}


Table Continued....

\begin{tabular}{|c|c|c|c|c|}
\hline Plant species & Plant part & Organic effluent & Remarks & Ref. \\
\hline Amaranthus gangeticus & Leaf & Congo red & Degradation completed within few minutes & 62 \\
\hline Phaseolus vulgaris & Fruit & Congo red & Showed $50 \%$ degradation & 63 \\
\hline Brassica oleracea capitata & Fruit & Congo red & Showed $50-60 \%$ degradation & 64 \\
\hline Punica grantum & Fruit & $\begin{array}{l}\text { Methylene blue, Methyl } \\
\text { orange, Eosin yellow }\end{array}$ & Followed first order kinetics & 55 \\
\hline Polygonum hydropiper & Leaf & Methylene blue & Degradation completed within 15 minutes & 52 \\
\hline Dillenia indica & Bark & $\begin{array}{l}\text { Methylene blue,4-Nitro } \\
\text { phenol }\end{array}$ & Degradation complete within 30 minutes & 51 \\
\hline Hyphaene thebaica & Fruit & $\begin{array}{l}\text { Congo red, 4-Nitro } \\
\text { phenol }\end{array}$ & $80 \%$ degradation occur within 10 minutes & 61 \\
\hline Actinidia deliciosa & Fruit & $\begin{array}{l}\text { Methylene blue, 4-Nitro } \\
\text { phenol }\end{array}$ & Degradation completed within few minutes & 72 \\
\hline Chenopodium aristatum & Stem & 4-Nitro phenol & Followed Langumir and Hinshel wood model kinetics & 73 \\
\hline Tapioca starch & $\begin{array}{l}\text { Analytical } \\
\text { grade }\end{array}$ & 4-Nitro phenol & Reduction completed within 15 minutes & 69 \\
\hline Lawsonia inermis & Leaf & 4-Nitro phenol & Reduction completed within 15 minutes & 70 \\
\hline Indigofera tinctoria & Leaf & $\begin{array}{l}\text { Ortho and para } \\
\text { Nitroanilines }\end{array}$ & Followed pseudo first order kinetics & 65 \\
\hline Elephantopus scaber & Leaf & $\begin{array}{l}\text { Ortho and para } \\
\text { Nitroanilines, 4-Nitro } \\
\text { phenol }\end{array}$ & Followed pseudo first order kinetics & 66 \\
\hline
\end{tabular}

\section{Photo catalytic degradation of dyes}

The photodegradation of methylene blue dye by silver nanoparticles from Helicteres isora, ${ }^{74}$ Anas platyrhynchos ${ }^{75}$ showed decrease in the absorption peak at $664 \mathrm{~nm}$ in the presence of light. The degradation reaction followed pseudo first order kinetics. In the proposed mechanism the excited surface electron interacts with dissolved oxygen which produced hydroxyl radicals which helped in the interaction of $\mathrm{Ag}^{+}$ions with dyes resulting in effective degradation. ${ }^{76}$ Smaller particle size, large surface area and capping phytochemicals effectively reduce the recombination of electrons leading to increase in the photo degradation efficiency of the biosynthesized Dimoncarpus longan, ${ }^{77}$ Casuarina equisetifolia ${ }^{78}$ silver nanoparticles. The silver nanoparticles acted as a catalyst by lowering the activation energy. ${ }^{77}$ Absorption peak of the dye decreased with increase in time of exposure to sunlight. ${ }^{79}$ The visible light irradiation of silver nanoparticles promoted electron from valence band to conduction band. ${ }^{80}$ The excited electrons in the conduction band were scavenged by lattice oxygen molecules on the surface of the catalyst to form a superoxide radical anion $\left(\mathrm{O}_{2}{ }^{-}\right){ }^{81}$ The newly formed oxygen anions further react with water to generate many oxidative species which causes dye degradation. ${ }^{82}$ Parkia roxburghii, ${ }^{83}$ and Diplazium esculentum ${ }^{84}$ silver nanoparticles showed effective degradation of methylene blue and rhodamine B through $\mathrm{NaBH}_{4}$, indicating that silver nanoparticles caused structural changes and removed chromophore group from the dye. ${ }^{83}$ The high potential difference among the donor and acceptor groups made the reaction kinetically unsuitable. The kinetic barrier could be removed by using silver catalyst that mediates the transfer of electron from donor $\left(\mathrm{BH}_{4}^{-}\right)$ to acceptor molecules. ${ }^{77}$ The reductions followed pseudo first order kinetics. The photocatalytic degradation by Solanum tuberosum, ${ }^{85}$ Hypnea musciformis, Ulva lactuca ${ }^{87}$ silver nanoparticles of methyl orange and Cordia dichotoma ${ }^{76}$ of congo red solution were initially low and further increased with regular increase in time. The probable mechanism of photocatalytic degradation by silver nanoparticles could be attributed to the surface plasmon resonance effect where the excited surface electrons might interact with the dissolved oxygen molecules and ultimately produce hydroxyl radicals while allowing $\mathrm{Ag}^{+}$ions to interact with the anionic dyes. ${ }^{76}$ Catalytic degradation process is initiated by the striking of colloidal silver nanoparticles by photons of sunlight and the degradation mechanism involving the excitation of conduction electrons of metallic Ag through surface plasmon resonance effect. ${ }^{88}$ Catalytic reduction of Allura red and Congo red, Eosin Y, Green Pls, Bromo phenyl blue under visible light was done using $\mathrm{NaBH}_{4}$ in presence of silver nanoparticles synthesised from Ekebergia capensis, ${ }^{89}$ Camellia japonica,${ }^{90}$ Dicrostachys cinerea,${ }^{91}$ and Cirsium japonicum ${ }^{80}$ extracts respectively. $\mathrm{NaBH}_{4}$ or sunlight alone is unable to bring about effective dye degradation. The presence of silver nanoparticles caused enrichment of the rate of reaction due to its electron relay effect for borohydride ions..$^{92} \mathrm{~A}$ summary of the various photocatalytic processes by silver nanoparticles are given in Table 2.

Table 2 Photocatalytic degradation by biosynthesised silver nanoparticles

\begin{tabular}{|c|c|c|c|c|}
\hline Plant species & Plant part & Organic effluent & Remarks & Ref. \\
\hline Casuarina equisetifolia & Cladode & Methylene blue & Photocatalytic degradation found to be effective & 78 \\
\hline Diplazium esculentum & Leaf & Methylene blue, Rhodamine B & Complete degradation within 8 minutes & 84 \\
\hline Solanum tubersom & Infusion & Methyl orange & Complete degradation within 8 hours & 85 \\
\hline
\end{tabular}


Table Continued....

\begin{tabular}{|c|c|c|c|c|}
\hline Plant species & Plant part & Organic effluent & Remarks & Ref. \\
\hline Anas platyrhynchos & Egg shell & $\begin{array}{l}\text { Methylene blue, Methyl violet 6B, } \\
\text { Rose Bengal }\end{array}$ & $\begin{array}{l}\text { Shown } 98.2 \%, 98.4 \% \text { and } 97 \% \text { degradations } \\
\text { respectively }\end{array}$ & 75 \\
\hline Helicteres isora & $\begin{array}{l}\text { Stem, leaf, } \\
\text { root }\end{array}$ & $\begin{array}{l}\text { Methyl violet, Safranin, Eosin, } \\
\text { Methylene blue, Methyl orange }\end{array}$ & Followed pseudo first order kinetics & 74 \\
\hline Ekebergia capensis & Leaf & Allura red, Congo red & Complete degradation within I hour & 89 \\
\hline Ulva lactuca & Whole plant & Methyl orange & Degradation within 12 hours & 87 \\
\hline Paederia foetida & Leaf & Rhodamine B & $\begin{array}{l}\text { Degradation kinetics fitted into pseudo first } \\
\text { order equation }\end{array}$ & 92 \\
\hline Cirsium japonicum & Whole plant & Bromo phenyl blue & Effective degradation was observed & 80 \\
\hline Camellia japonica & Leaf & Eosin $Y$ & Complete degradation within I hour & 90 \\
\hline Parkia roxburghii & Leaf & Methylene blue, Rhodamine B & Complete degradations within 12 minutes & 83 \\
\hline Dimoncarpus longan & Seed & Methylene blue, 4-Nitro phenol & Followed first order kinetics & 77 \\
\hline Cordia dichotoma & Leaf & Methylene blue, Congo red & Highly potential photocatalytic activity & 76 \\
\hline Dicrostachys cinerea & Leaf & Green Pls & Complete degradation within 120 minutes & 91 \\
\hline
\end{tabular}

\section{Conclusion}

Green synthesis of silver nanoparticles is a compatible, ecofriendly, low cost, and less time consuming process. It is found that the use of natural renewable and eco-friendly reducing agents for the synthesis of silver nanoparticles exhibits rapid and excellent photocatalytic activity against different dyes compared to other degradation techniques like biodegradation. These make them potential candidates for water purification systems and dye effluent treatment. The application of nanomaterials offered opportunities for upgrading the conventional methods or generating innovative methods to deal with the dye contaminants with high efficiency.

\section{Acknowledgements}

None.

\section{Conflict of interest}

Author declares there is no conflict of interest.

\section{References}

1. Oliveira LS, Franca AS, Alves TM, et al. Evaluation of untreated coffee husks as potential biosorbents for treatment of dye contaminated waters. J Hazard Mater. 2008;155(3):507-512.

2. Yu K, Yang SG, Liu C, et al. Environ Sci Technol. 2012;46:7318-7326.

3. Nasrollahzadeh M, Atarod M, Jaleh B, et al. In situ green synthesis of Ag nanoparticles on graphene oxide/ $\mathrm{TiO}_{2}$ nanocomposite and their catalytic activity for the reduction of 4-nitrophenol, congo red and methylene blue. Ceramics International. 2016;42(7):8587-8596.

4. Mori T, Watanuki T, Kashiwaguru T, et al. Diesel exhaust particles disturb gene expression in mouse testis. Environ Toxicol. 2007;22(1):58-63.

5. Nemanashi M, Meijboom R. Synthesis and characterization of $\mathrm{Cu}, \mathrm{Ag}$ and $\mathrm{Au}$ dendrimer-encapsulated nanoparticles and their application in the reduction of 4-nitrophenol to 4-aminophenol. J Colloid Interface Sci. 2013;389(1):260-267.
6. Cooper P. J Soc Dyers Colourists. 1993;109:97-101.

7. Alaton IA, Balcioglu IA. Photochemical and heterogeneous photocatalytic degradation of waste vinylsulphone dyes: a case study with hydrolysed Reactive Black 5. J Photochem Photobiol. 2001;141:247-254.

8. Faisal M, Tariq MA, Muneer M, et al. Photocatalysed degradation of two selected dyes in UV-irradiated aqueous suspensions of titania. Dyes Pigm. 2007;72(2):233-239.

9. Dabrowski A. Adsorption-From Theory to Practice. Adv Colloid Interface Sci. 2001;93:135-224.

10. Slokar YM, Marechal AML. Le Marechal. Methods of Decoloration of Textile Wastewaters. Dyes Pigm. 1998;37(4):335-356.

11. Kurniawan TA, Chan GYS, Lo WH, et al. Physico-chemical treatment techniques for wastewater laden with heavy metals. Chem Eng $J$. 2006;118(1-2):83-98.

12. Pedersen AJ. Characterization and electrodialytic treatment of wood combustion fly ash for the removal of cadmium. Biomass Bioenergy. 2003;25:447-458.

13. Tang WZ, An $\mathrm{H}$. UV/TiO 2 photocatalytic oxidation of commercial dyes in aqueous solutions. Chemosphere. 1995;31(9):4157-4170.

14. Ghoreishi SM, Haghighi R. Chemical catalytic reaction and biological oxidation for treatment of non-biodegradable textile effluent. Chem Eng J. 2003;95(3):163-169.

15. Pereira MFR, Soares SF. Adsorption of dyes on activated carbons: influence of surface chemical groups. Carbon. 2003;41(4):811-821.

16. Marco A, Esplugas S, Saum G, et al. Water Sci Technol. 1997;35:231327.

17. Ghoreishi SM, Haghighi R. Chemical Catalytic Reaction and Biological Oxidation for Treatment of Non-Biodegradable Textile Effluent. Chem Eng J. 2003;95:163-169.

18. McMullan G, Meehan C, Conneely A, et al. Microbial decolourisation and degradation of textile dyes. Appl Microbiol Biotechnol. 2001;56(2):8187. 
19. Fu Y, Viraraghavan T. Fungal decolorization of dye wastewaters: a review. Bioresour Technol. 2001;79(3):251-262.

20. Robinson T, McMullan G, Marchant R, et al. Remediation of dyes in textile effluent: a critical review on current treatment technologies with a proposed alternative. Bioresour Technol. 2001;77(3):247-255.

21. Kumar FV, Wati L, Nigam P, et al. Process Biochem. 1998;33:83-88.

22. Wang Y, Liu L, Xu L, et al. Nanoscale. 2014;6(11):6790-6800.

23. Wang J, Sun Q, Wang W, et al. J Mater Chem. 2009;19:6597-6605.

24. El-Kemary M, Abdel-Moneam Y, Madkour M, et al. Enhanced photocatalytic degradation of safranin-O by heterogeneous nanoparticles for environmental applications. J Lumin. 2011;131:570-576.

25. Ullah R, Dutta J. Photocatalytic degradation of organic dyes with manganese-doped ZnO nanoparticles. J Hazard Mater. 2008;156(3):194200 .

26. Wu ZC, Zhang Y, Tao TX, et al. Appl Surf Sci. 2010;257:1092-1097.

27. Bahnemann DW, Kormann C, Hoffmann MR, et al. Preparation and Characterization of Quantum Size Zinc Oxide: A Detailed Spectroscopic Study. J Phys Chem. 1987;91:3789-3794.

28. Han C, Likodimos V, Khan JA, et al. Environ Sci Pollut Res. 2004;21:11781-11793.

29. Anpo M. Use of visible light. Second-generation titanium oxide photocatalysts prepared by the application of an advanced metal ionimplantation method. Pure Appl Chem. 2000;72:1787-1792.

30. Ghosh SK, Kundu S, Mandal M, et al. Silver and Gold Nanocluster Catalyzed Reduction of Methylene Blue by Arsine in a Micellar Medium. Langmuir. 2002;18:8756-8760.

31. Pal T, De S, Jana NR, et al. Organized Media as Redox Catalysts. Langmuir. 1998;14(17):4724-4730.

32. Jingquan C, Suwei Y, Weiguo Z, et al. Front Chem China. 2006;4:418422 .

33. Gonzalez CM, Liu Y, Scaiano JC, et al. J Phys Chem C. 2009;113:1186111867.

34. Ankamwar B, Damle C, Ahmad A, et al. Biosynthesis of gold and silver nanoparticles using Emblica Officinalis fruit extract, their phase transfer and transmetallation in an organic solution. J Nanosci Nanotechnol. 2005;5(10):1665-1671.

35. Singaravelu G, Arockiamary JS, Kumar VG, et al. Colloids Surf B Biointerfaces. 2007;57:97-101.

36. Prasad K, Jha AK, Kulkarni AR, et al. Lactobacillus assisted synthesis of titanium nanoparticles. Nanoscale Res Lett. 2007;2:248-250.

37. Shankar SS, Rai A, Ahamad A, et al. Rapid synthesis of Au, Ag, and bimetallic Au core-Ag shell nanoparticles using Neem (Azadirachta indica) leaf broth. J Colloid Interf Sci. 2004;275(2):496-502.

38. Krishnaraj C, Jagan EG, Rajasekar S, et al. Synthesis of silver nanoparticles using Acalypha indica leaf extracts and its antibacterial activity against water borne pathogens. Colloids Surf B Biointerfaces. 2010;76(1):50-56.

39. Tripathi A, Chandrasekaran N, Raichur AM, et al. Antibacterial applications of silver nanoparticles synthesized by aqueous extract of Azadirachta indica (Neem) leaves. J Biomed Nanotechnol. 2009;5(1):9398.

40. Grogger C, Fattakhov SG, Jouikov VV, et al. Primary steps of oxidation and electronic interactions in anodic cleavage of $\alpha, \omega$-diisocyanurate substituted dialkyl disulfides. Electrochim Acta. 2004;49(19):31853194.
41. Pradhan N, Pal A, Pal T, et al. Silver Nanoparticle Catalyzed Reduction of Aromatic Nitro Compounds.Colloids Surf A Physicochem Eng Asp. 2002; 196:247-257.

42. Mallick K, Witcomb M, Scurrell M, et al. Mater Chem Phys. 2006;97:283-287.

43. Sinha T, Ahmaruzzaman M. High-value utilization of egg shell to synthesize Silver and Gold-Silver core shell nanoparticles and their application for the degradation of hazardous dyes from aqueous phase-A green approach. J Colloid Interface Sci. 2015;453:115-131.

44. da Silva CG, Faria JL. Photochemical and photocatalytic degradation ofan azo dye in aqueous solution by UV irradiation. $J$ Photochem Photobiol A Chem. 2003;155:133-143.

45. Suvith VS, Philip D. Catalytic degradation of methylene blue using biosynthesized gold and silver nanoparticles. Spectrochim Acta A Mol Biomol Spectrosc. 2014;118:526-532.

46. Naraginti S, Li Y. Preliminary investigation of catalytic, antioxidant, anticancer and bactericidal activity of green synthesized silver and gold nanoparticles using Actinidia deliciosa. J Photochem Photobiol B. 2017; 170:225-234.

47. Hamedi S, Shojaosadati SA, Mohammadi A, et al. J Photochem Photobiol B. 2017;167:36-44.

48. Sowmyya T, Lakshmi GV. World J Pharm Pharm Sci. 2015;5:786-805.

49. Manjari G, Saran S, Arun T, et al. Facile Aglaia elaeagnoidea Mediated Synthesis of Silver and Gold Nanoparticles: Antioxidant and Catalysis Properties. J Clust Sci. 2017;28(4):2041-2056.

50. Saha J, Begum A, Mukherjee A, et al. Sustain Environ Res. 2017;27:245250 .

51. Mohanty AS, Jena BS. Innate catalytic and free radical scavenging activities of silver nanoparticles synthesized using Dillenia indica bark extract. J Colloid Interface Sci. 2017;496:513-521.

52. Bonnia NN, Kamaruddin MS, Nawawi MH, et al. Green Biosynthesis of Silver Nanoparticles Using 'Polygonum Hydropiper' and Study its Catalytic Degradation of Methylene Blue. Procedia Chem. 2016;19:594 602.

53. Vadivu BS, Sivasankari R, kumar KS, et al. Glob J Eng Sci Res Manag. $2017 ; 4: 26-32$

54. Joseph S, Mathew B. Microwave-assisted green synthesis of silver nanoparticles and the study on catalytic activity in the degradation of dyes. J Mol Liq. 2015;204:184-191.

55. Meena Kumari M, Philip D. Degradation of environment pollutant dyes using phytosynthesized metal nanocatalysts. Spectrochim Acta Mol Biomol Spectrosc. 2015;135:632-638.

56. Jyoti K, Singh A. Genet Eng Biotechnol J. 2016;14:311-317.

57. Alzahrani E. Eco-Friendly Production of Silver Nanoparticles from Peel of Tangerine for Degradation of Dye. World J Nanosci Eng. 2015;5:1016

58. Varadavenkatesan T, Selvaraj R, Vinayagam R, et al. Phyto-synthesis of silver nanoparticles from Mussaenda erythrophylla leaf extract and their application in catalytic degradation of methyl orange dye. J Mol Liq. 2016;221:1063-1070.

59. Bhankhar A, Giri M, Yadav K, et al. Study on degradation of methyl orange-anazo dye by silver nanoparticles using UV-Visible spectroscopy. Indian J Phys. 2014;88:1191-1196.

60. Edison TNJI, Atchudan R, Sethuraman MG, et al. Reductive-degradation of carcinogenic azo dyes using Anacardium occidentale testa derived silver nanoparticles. Photochem Photobiol B. 2016;162:604-610. 
61. Bello BA, Khan SA, Khan JA, et al. Biochem Biophys Res Commun 2017;490:889-894.

62. Kolya H, Maiti P, Pandey A, et al. J Anal Sci Technol. 2015;6:33-40.

63. Deb S. Int J Chem Tech Res. 2014;6:3909-3917.

64. Sunkar S, Nachiyar CV, Karunya A, et al. Phytogenic Silver Nanoparticle Synthesis with Potential Antibacterial Activity and Dye Degrading Ability. Res J Pharm Biol Chem Sci. 2013;4:1088-1097.

65. Vijayan R, Joseph S, Mathew B, et al. Artif Cells Nanomed Biotechnol. 2018;46:861-871.

66. Francis S, Joseph S, Koshy EP, et al. Microwave assisted green synthesis of silver nanoparticles using leaf extract of elephantopus scaber and its environmental and biological applications. Artif Cells Nanomed Biotechnol. 2018;46:795-804.

67. Gangula A, Podila R, Karanam L, et al. Catalytic Reduction of 4-Nitrophenol using Biogenic Gold and Silver Nanoparticles Derived from Breynia rhamnoides. Langmuir. 2011;27:15268-15274.

68. Kundu S, Mandal M, Ghosh SK, et al. Photochemical deposition of SERS active silver nanoparticles on silica gel and their application as catalysts for the reduction of aromatic nitro compounds. J Colloid Interface Sci. 2004;272:134-144.

69. Kalantari K, Afifi ABM, Bayat S, et al. Heterogeneous catalysis in 4-nitrophenol degradation and antioxidant activities of silver nanoparticles embedded in Tapioca starch. Arab J Chem. 2017.

70. Ajitha B, Reddy YAK, Reddy PS, et al. Instant biosynthesis of silver nanoparticles using Lawsonia inermis leaf extract: Innate catalytic, antimicrobial and antioxidant activities. J Mol Liq. 2016;219:474-481.

71. Joseph S, Mathew B. Microwave assisted facile green synthesis of silver and gold nanocatalysts using the leaf extract of Aerva lanata. Spectrochim Acta Mol Biomol Spectrosc. 2015;136:1371-1379.

72. Naraginti S, Li Y. Preliminary investigation of catalytic, antioxidant, anticancer and bactericidal activity of green synthesized silver and gold nanoparticles using Actinidia deliciosa. J Photochem Photobiol B. 2017;170:225-234.

73. Yuan CG, Huo C, Gui B, et al. J Clust Sci. 2017;28:1319-1333.

74. Bhakya S, Muthukrishnan S, Sukumaran M, et al. J Bioremed Biodeg 2015;6:312-321.

75. Sinha T, Ahmaruzzaman M. High-value utilization of egg shell to synthesize Silver and Gold-Silver core shell nanoparticles and their application for the degradation of hazardous dyes from aqueous phase-A green approach. J Colloid Interface Sci. 2015;453:115-131.

76. Kumari RM, Thapa N, Gupta N, et al. Adv Nat Sci: Nanosci Nanotechnol. 2016;164:344-351.

77. Khan FU, Chen Y, Khan NU, et al. Antioxidant and catalytic applications of silver nanoparticles using Dimocarpus longan seed extract as a reducing and stabilizing agent. J Photochem Photobiol B. 2016;164:344351 .
78. Saranya VTK, Gowrie SU, et al. Indo Am J pharm res. 2016;6:45624568.

79. Mendhulkar VD, Yadav A, Khamkar S, et al. Pharm Lett. 2016;8:119128.

80. Khan ZU, Khan A, Shah A, et al. J Mol Liq. 2016;220:248-257.

81. Karthik R, Govindasamy M, Chen SM, et al. Biosynthesis of silver nanoparticles by using Camellia japonica leaf extract for the electrocatalytic reduction of nitrobenzene and photocatalytic degradation of Eosin-Y. J Photochem Photobiol B. 2017;170:164-172.

82. Ashok D, Sandupatla R, Koyyati R, et al. Int J Chem Tech Res. 2017;10:302-314.

83. Paul B, Bhuyan B, Purkayastha DD, et al. Green synthesis of silver nanoparticles using dried biomass of Diplazium esculentum (retz.) sw. and studies of their photocatalytic and anticoagulative activities. $J \mathrm{Mol}$ Liq. 2015;212:813-817.

84. Paul B, Bhuyan B, Purkayastha DD, et al. Photocatalytic and antibacterial activities of gold and silver nanoparticles synthesized using biomass of Parkia roxburghii leaf. J Photochem Photobiol B. 2016;154:1-7.

85. Roy K, Sarkar CK, Ghosh CK, et al. Photocatalytic activity of biogenic silver nanoparticles synthesized using potato (Solanum tuberosum) infusion. Spectrochim Acta A Mol Biomol Spectrosc. 2015;146:286-291.

86. Ganapathy Selvam G, Sivakumar K. Phycosynthesis of silver nanoparticles and photocatalytic degradation of methyl orange dye using silver (Ag) nanoparticles synthesized from Hypnea musciformis (Wulfen) J.V. Lamouroux. Appl Nanosci. 2015;5:617-622.

87. Kumar P, Govindaraju M, Senthamilselvi S, et al. Photocatalytic degradation of methyl orange dye using silver (Ag) nanoparticles synthesized from Ulva lactuca. Colloids Surf B. 2013;103:658-661.

88. Yu L, Xi J, Li M, et al. The degradation mechanism of methyl orange under photo-catalysis of $\mathrm{TiO}_{2}$. Phys Chem Chem Phys. 2012;14:35893595 .

89. Anand K, Kaviyarasu K, Muniyasamy S, et al. J Clust Sci. 2017;28:22792291.

90. Karthik R, Govindasamy M, Chen SM, et al. Biosynthesis of silver nanoparticles by using Camellia japonica leaf extract for the electrocatalytic reduction of nitrobenzene and photocatalytic degradation of Eosin-Y. J Photochem Photobiol B. 2017;170:164-172.

91. Paau MC, Lo CK, Yang X, et al. J Phys Chem C. 2010;114:15995-16003.

92. Bhuyan B, Paul A, Paul B, et al. Paederia foetida Linn. promoted biogenic gold and silver nanoparticles: Synthesis, characterization, photocatalytic and in vitro efficacy against clinically isolated pathogens. J Photochem Photobiol B. 2017;173:210-215. 